\title{
Fast and Efficient Monitoring of Diclofenac Dissolution Profile by CE
}

\author{
Celina M. Monzón ${ }^{1}$, Luciana Vera-Candioti ${ }^{2}$, María del C. Sarno ${ }^{1}$ and Mario R. Delfino ${ }^{1}(\mathrm{~h})$
}

${ }^{I}$ School of Exact and Natural Sciences - Northeastern National University (UNNE), Instrumental Analysis LaboratoryAv. Libertad 5640-Corrientes- Argentina; ${ }^{2}$ School of Biochemistry and Biological Sciences - Litoral National University (UNL), Analytical Development and Quimiometry Laboratory (LADAQ)- Santa Fe-Argentina

\begin{abstract}
Capillary electrophoresis (CE) was used to follow Diclofenac tablet dissolution, in very short times and allowing dissolution testing without volume replacement. By using Student's t test and F-test, this CE method was compared with HPLC. Statistical data show that there are no significant differences among them. The drug release kinetic of diclofenac tablets was described by various mathematical models and equations. Model-Independent Methods: $\mathrm{t}_{50 \%}=10.34$ $\min ; \mathrm{t}_{80 \%}=20 \mathrm{~min} ; \mathrm{DE} \%=79.41 \%$ and $\mathrm{MDT}=10.85 \mathrm{~min}$, show that diclofenac tablet dissolution rate is very high, having $80 \%$ drug dissolution within 20 minutes. Model-Dependent Methods. The kinetics models used were: zero order, first order, Hixson-Crowell cube root law, Higuchi model, and Weibull model. Criteria used to choose the best model was by comparisson of $\mathrm{r}^{2}$ and AIC (Akaike Information Criteria). The model that best adjusts diclofenac tablet dissolution profile was the Hixson-Crowell cube root model.
\end{abstract}

Keywords: Capillary electrophoresis, diclofenac, dissolution, Hixson-Crowell, quantification, tablets.

\section{INTRODUCTION}

Among Non-Steroidal Anti-Inflammatory Drugs (NSAID) Diclofenac sodium 2-[2-[(2,6-dichlorophenyl) amino]phenyl]acetate (Fig. 1) can be found. This drug is mainly used as an analgesic reducing pain and inflammation, in medical conditions such as rheumatoid arthritis, ankylosing spondylitis and osteoarthritis [1].

Tablets of $50 \mathrm{mg}$ of diclofenac are produced by the Medicinal Plant of Corrientes (PLAMECOR) under The Ministry of Public Health. These are distributed without cost in primary care centers across the province.

USP (United States Pharmacopoeia) recommends diclofenac determination by liquid chromatography methods [2-4]. Diclofenac determinations by electrochemical techniques are the main research interests: cyclic voltammetry [5]; potentiometric sensor [6]; capillary electrophoresis [79]; spectrophotometric methods are also studied [10-12]. Other authors focus on diclofenac quantification in vivo using HPLC-MS [13, 14]. A great deal of research papers are focused on official method validation concerning drug release from dosage forms [15-19].

In adition, ANMAT (National Drug, Food and Medical Technology Administration of Argentina), has not yet established analytical methods for diclofenac tablets quality control [20].

Capillary Electrophoresis (CE) is a powerful analytical tool that allows separation and analyte quantification in much shorter times than HPLC [21, 22], reducing reagent

*Address correspondence to this author at the School of Exact and Natural Sciences - Northeastern National University (UNNE), Instrumental Analysis Laboratory- Av. Libertad 5640- Corrientes- Argentina; Tel: +54-3794457996; Fax: +54-379-4473930; E-mail: mcsarno@exa.unne.edu.ar and solvent demand, being more "eco-friendly" than HPLC. In addition sample volume requirements are lower than HPLC allowing dissolution testing without volume replacement. When a solid dosage form of a drug is administered orally, its absorption depends on several processes such as: release of the active principle, drug solubilization or dissolution under physiological conditions, and permeability across the gastrointestinal tract. In vivo performance can be predicted by evaluating in vitro dissolution. The drug release kinetic of the diclofenac tablets provided by PLAMECOR was described by various mathematical models and equations [23-25].<smiles>O=C(O)Cc1ccccc1Nc1c(Cl)cccc1Cl</smiles>

Fig. (1). Diclofenac sodium chemical structure.

\section{MATERIALS AND METHODS}

\subsection{Samples and Reagents}

Diclofenac in pure form lot 1004-30-5 (powder), origin China, (99.99\% purity, determined by HPLC method) and diclofenac $50 \mathrm{mg}$ tablets lot $\mathrm{N}^{\mathrm{o}} 112 / 12$ from PLAMECOR were used. 
Acetaminophen in pure form lot 4120374 (powder), origin China, (99.99 \% purity, determined by HPLC method) from PLAMECOR, was used as internal standard.

Placebo used in specificity and accuracy determinations, was provided by PLAMECOR and its composition is the same present in the tablet: magnesium stearate $1 \%$, talc $2 \%$, sodium starch glycolate $3.5 \%$, polyvinylpyrrolidone (PVP) $1.2 \%$ and $73.2 \%$ green precompact powder.

All reagents were of analytical grade. Sodium hydroxide, sodium borate, sodium phosphate, hydrochloric acid and methanol were purchased from Merck (Darmstadt, Germany). Ultra-pure water was obtained from an ultra-pure water purification system from Millipore (Bedford, MA, USA) and was used in all the CE experiments.

Stock standard solutions of diclofenac and acetaminophen were prepared at a concentration of $2000 \mathrm{ppm}$ by dissolving the accurately weighed amount of each drug in water. Working standard solutions were prepared by dissolving stock standard solutions in water.

Sample preparation: a stock sample solution was prepared at a concentration of $2000 \mathrm{ppm}$ by dissolving the accurately weighed amount of a pool of 10 diclofenac tablets, in water. Working tablet solutions were prepared by dissolving the stock sample solution in water.

Internal standard procedure: an accurate and precise volume of acetaminophen $70 \mathrm{ppm}$ (internal standard solution) was added to diclofenac working standard solution and diclofenac sample solution so that they both contain an identical concentration of internal standard.

The $\mathrm{pHs}$ of the background electrolyte (BGE) solutions were adjusted by a pHmeter (HANNA Instrument). All solutions were degassed in an ultrasonic bath Cole Palmer 8891 (Cole Palmer, Illinois, USA) and filtered through $0.45 \mu \mathrm{m}$ nylon membrane (Sartorius, Germany) before use.

\subsection{Instrumentation and Electrophoretic Procedure}

All experiments were carried out on a capillary electrophoresis system (Agilent Technologies, Waldbronn, Germany), equipped with a diode array detector. Separation was carried out in an uncoated fused-silica capillary of $35.5 \mathrm{~cm}$ total length (effective length $27 \mathrm{~cm}$ ), with an inner diameter of $75 \mu \mathrm{m}$ (MicroSolv Technology Corporation, Eatontown, NJ, USA) in a normal mode, applying a voltage of $20 \mathrm{kV}$, with a typical current of about $85 \mu \mathrm{A}$.

The cartridge was maintained at $25.0{ }^{\circ} \mathrm{C}$. The wavelength used for recording the electropherograms was 200 $\mathrm{nm}$. Injection was made from the positive electrode of the capillary hydrodynamically applying 50 mbar of pressure for $10 \mathrm{~s}$.

A careful activation and conditioning of the capillary was essential in order to obtain reproducible results and to remove substances adsorbed to the capillary wall. Thus, at the beginning of every working day the capillary was rinsed with: sodium hydroxide $0.1 \mathrm{M}(10 \mathrm{~min})$, ultra-pure water $(10 \mathrm{~min})$ and sodium borate solution $15 \mathrm{mM} \mathrm{pH} 9.2$ (10 min) which is the BGE. Between runs the capillary was successively flushed with sodium hydroxide $0.1 \mathrm{M}$, ultra-pure water and BGE for 3 min each. At the end of the day the capillary was washed with sodium hydroxide $0.1 \mathrm{M}$ (5 min), ultra-pure water $(5 \mathrm{~min})$ and then air-dried for $3 \mathrm{~min}$.

\subsection{Method Validation}

For linearity study a calibration curve was constructed with diclofenac pure form in a concentration range between 50 and $90 \mathrm{ppm}$.

Specificity was assessed by electrophoretic runs of placebo prepared with excipients in the same proportion as found in $50 \mathrm{mg}$ diclofenac tablets.

Precision was analyzed as repeatability. A number of 6 samples were analyzed by triplicate on the same day, by the same operator, using the same instrument. ANOVA test was performed to analyze the data using Excel $^{\mathbb{B}}$ (Microsoft).

Accuracy was based on the recovery of known amounts of analyte in placebo. Spiked samples with different levels of diclofenac $(80,100$ and $120 \%$ tablet concentration), were prepared. The analysis was done in triplicate [26].

\subsection{HPLC -UV Analysis}

HPLC (Agilent 1120 series compact LC) equipped with a UV detector was used.

For diclofenac measurement mobile phase consisting of a filtered and degassed mixture of methanol and phosphate buffer $\mathrm{pH} 2.5$ (70:30) was used. Diluent was a methanol and water mixture (70:30). Column: RP-18C, 125x4.5 mm. Flow rate was $1 \mathrm{~mL} / \mathrm{min}$. Detection wavelength was set at $276 \mathrm{~nm}$. Injection volume was $20 \mu \mathrm{L}$. Diclofenac pure form $70 \mathrm{ppm}$ solution and Diclofenac tablets solution $81 \mathrm{ppm}$ were used. Identity was verified with diclofenac retention time $(8.2 \mathrm{~min})$. Peak areas were determined. Conversion of peak area (A) to concentration levels $(\mathrm{C})$ was based on equation 1 .

$\mathrm{C}_{\text {sample }}=\mathrm{C}_{\text {diclo }} \cdot \mathrm{A}_{\text {diclo }} / \mathrm{A}_{\text {sample }}$

\subsection{Dissolution}

Drug dissolution profile was evaluated employing USP basket method, with a Dissolutor AVIC D-II. Dissolution testing was carried out under physiological conditions. The volume of the dissolution medium was $900 \mathrm{~mL}$. To simulate intestinal fluid, a phosphate buffer solution of $\mathrm{pH} 7.4$ was employed. Tests were conducted at $37 \pm 0.5^{\circ} \mathrm{C}$. Mild agitation conditions were maintained during dissolution testing. Agitation (or stirring speed) was $50 \mathrm{rpm}$.

The selected time points for the dissolution profile were: $0,5,10,15,20,25,30,45$ and $60 \mathrm{~min}$.

An aliquot of $500 \mu \mathrm{L}$ was withdrawn from the dissolutor at these time intervals. The sample solution extracted from the dissolutor and $17.5 \mu \mathrm{L}$ acetaminophen (internal standard solution) were brought to $2 \mathrm{~mL}$ with MilliQ quality water. Samples were filtered through $0.45 \mu \mathrm{m}$ nylon membrane before use.

Samples were analyzed using CE. In the data analysis, percentage of drug release was calculated using a mean of three sample measurements. 


\subsection{Drug Release Kinetics}

\subsubsection{Model-Independent Methods}

The model-independent approaches performed to characterize drug release were: $t_{x} \%$, time necessary to release a determined percentage of drug $\left(\mathrm{t}_{50 \%}\right.$ and $\left.\mathrm{t}_{80 \%}\right)$; Dissolution efficiency (DE), based on equation 2 , area under the dissolution curve up to a certain time, $t$, expressed as a percentage of the area of the rectangle described by $100 \%$ dissolution in the same time; and Mean Dissolution Time (MDT), equation 3.

$\operatorname{DE}(\%)=100 \cdot \mathrm{ABC}_{0}^{\mathrm{T}} / \mathrm{Q}_{100} \cdot \mathrm{T}$

$\operatorname{MDT}=\Sigma\left[\mathrm{t}_{\mathrm{i}} . \Delta \mathrm{Q}_{\mathrm{i}}\right] / \mathrm{Q}_{\infty}$

\subsubsection{Model-Dependent Methods}

The kinetics models used were: zero order, as cumulative amount of drug release vs.time; first order as ln cumulative percentage of drug remaining vs. time; Hixson-Crowell cube root law, as cube root percent drug remaining vs. time; Higuchi model, as cumulative percentage of drug release vs. square root of time; and Weibull model, as $\ln$ dissolved amount of drug vs. ln of time (Table 1).

\section{RESULTS AND DISCUSSION}

Electropherogram of diclofenac pure form (Fig. 2).

\subsection{Method Validation}

Calibration Curve: plotting area ratio (diclofenac/ acetaminophen) vs. Diclofenac concentration, a good linearity has

Table 1. Model-dependent methods.

\begin{tabular}{|c|c|}
\hline Zero order & $\mathrm{Q}_{1}=\mathrm{Q}_{0}+\mathrm{K}_{0} \cdot \mathrm{t}$ \\
\hline First order & $\ln \mathrm{Q}_{1}=\ln \mathrm{Q}_{0}+\mathrm{K}_{1} \cdot \mathrm{t}$ \\
\hline Hixson-Crowell & $\mathrm{Q}_{0}{ }^{1 / 3}-\mathrm{Q}_{1}{ }^{1 / 3}=\mathrm{K}_{1} \cdot \mathrm{t}$ \\
\hline Higuchi & $\mathrm{Q}_{1}=\mathrm{K}_{\mathrm{H} \cdot \mathrm{t}^{1 / 2}}$ \\
\hline Weibull & $\ln \left\{\ln \left[\mathrm{Q}_{\infty} /\left(\mathrm{Q}_{\infty} \mathrm{Q}\right)\right]\right\}=\beta \cdot \ln \left(\mathrm{t}-\mathrm{t}_{0}\right)-\beta \cdot \ln \mathrm{t}_{\mathrm{d}}$ \\
\hline
\end{tabular}

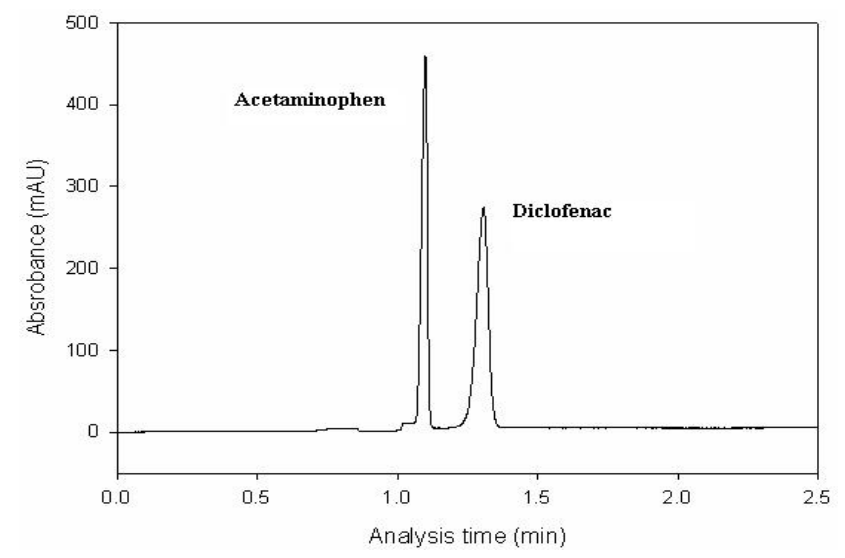

Fig. (2). Diclofenac pure form electropherogram. Voltage of $20 \mathrm{kV}$, current $85 \mu \mathrm{A}$. Electropherograms were recorded at $200 \mathrm{~nm}$. Injection was made hydrodynamically applying $50 \mathrm{mbar}$ of pressure for $10 \mathrm{~s}$. BGE: sodium borate solution $15 \mathrm{mM} \mathrm{pH} \mathrm{9.2.}$ been found from the regression analysis $[y=(0.0208 \pm$ $0.0007) \mathrm{x}-(0.0292 \pm 0.0479)]$ with $\mathrm{r}^{2}=0.9972$ with a $95 \%$ confidence level. Linear range of the essay was $50-90 \mathrm{ppm}$ (Fig 3).

Electrophoretic analysis of placebo demonstrates the chemical inertia of diclofenac tablets excipients, and therefore method specificity (Fig. 4).

The proposed method was found to be highly precise, having a Relative Standard Deviation for repeatability $(n=10)$ of $1.72 \%$, below the maximum amount accepted by the pharmacopoeias for pharmaceutical preparations $(\mathrm{SD} \% \leq 2 \%)$.

Accuracy: recovery of analyte in placebo 100.36 $103.47 \%$, values that fall within the requirements set by USP and ANMAT. (Table 2).

This CE method was compared with HPLC [26]. ANOVA test was performed to analyze the data Results are shown in Table 3. Statistical data obtained by using Student's t-test and F-tests show no significant difference between the methods ( $p>0.05$ ). A confidence level of $95 \%$ was considered.

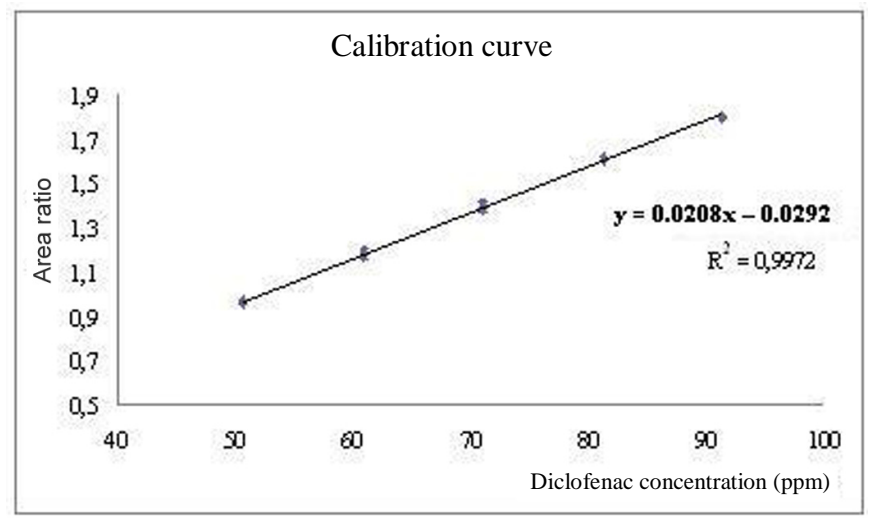

Fig. (3). Calibration curve, (diclofenac/acetaminophen area) vs. Diclofenac concentration (ppm).

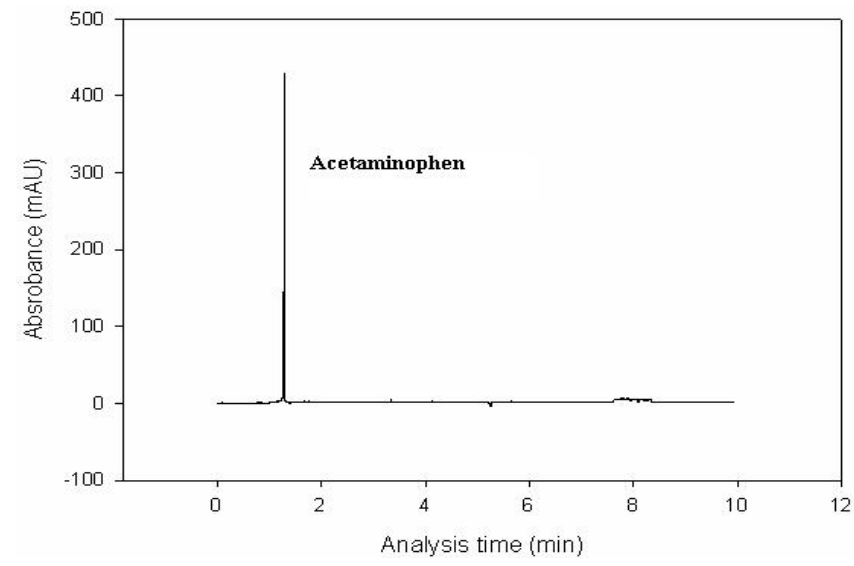

Fig. (4). Placebo electropherogram. 


\subsection{Dissolution Profile}

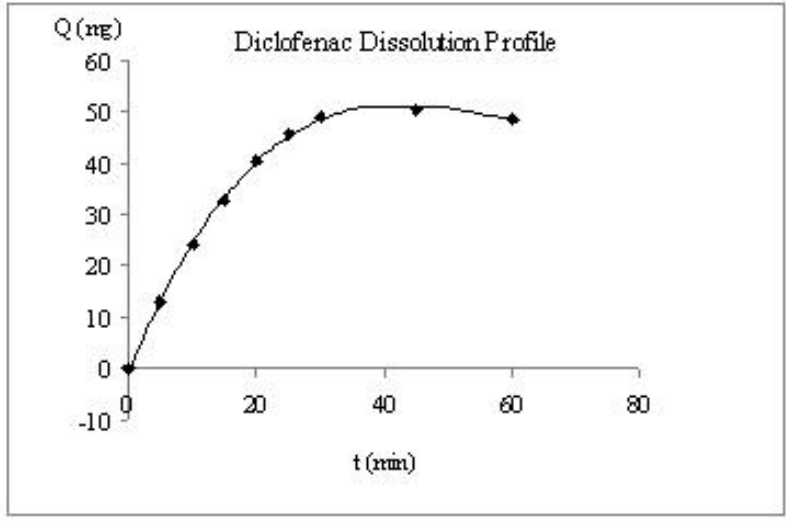

Fig. (5). Diclofenac dissolution profile.

\subsection{Drug Release Kinetics}

\subsubsection{Model-Independent Methods}

Calculated parameters:

$\mathrm{t}_{50 \%}=10.34 \mathrm{~min}$

$\mathrm{t}_{80 \%}=20 \mathrm{~min}$

$\mathrm{DE} \%=79.41 \%$

$$
\mathrm{MDT}=10.85 \mathrm{~min}
$$

These results show that Diclofenac tablet dissolution rate is very high, having $80 \%$ drug dissolution within 20 minutes.

\subsubsection{Model-Dependent Methods}

Fig. (6). shows the results of the kinetic models used.

The criteria used to choose the best model was by comparisson of $\mathrm{r}^{2}$ and AIC (Akaike Information Criteria). The highest adjusted $r^{2}$ and the lowest AIC determine the model that best adjusts diclofenac dissolution profile. (Table 4).

Based on these two criteria, the model that best adjusts diclofenac dissolution profile was the Hixson-Crowell cube root model, in wich the surface area of the tablet exposed to the dissolution medium, varies throughout the process as a function of the cubic root of the squared volume of the solid.

\section{CONCLUSION}

The CE method has been confirmed to be useful for the quality control of diclofenac $50 \mathrm{mg}$ tablets, without interference from common excipients. This method was found to be simple, rapid and specific, allowing separation and analyte quantification in much shorter times, reducing reagent and solvent demand, being more "eco friendly" than HPLC. In addition sample volume requirements in $\mathrm{CE}$ are lower than

Table 2. Accuracy (recovery of analyte in placebo).

\begin{tabular}{|c|c|}
\hline Diclofenac Percentage of Tablet Concentration \% & Recovery of Analyte in Placebo \% \\
\hline \hline \multirow{2}{*}{80} & 101.18 \\
\cline { 2 - 3 } & 101.09 \\
\hline \multirow{2}{*}{100} & 102.79 \\
\cline { 2 - 3 } & 102.14 \\
\hline \multirow{2}{*}{120} & 101.69 \\
\cline { 2 - 3 } & 102.93 \\
\cline { 2 - 3 } & 102.02 \\
\hline
\end{tabular}

Table 3. Statistical comparison of the $\mathrm{CE}$ method with the reference method.

\begin{tabular}{|c|c|c|}
\hline Parameter & CE Method & HPLC-UV Method \\
\hline \hline $\mathrm{Xm} \pm \mathrm{SD}$ & $48.1 \pm 0.8$ & $49.5 \pm 0.7$ \\
\hline $\mathrm{RSD} \%$ & 1.73 & 1.38 \\
\hline $\mathrm{S}^{2}$ & 0.69 & 0.47 \\
\hline $\mathrm{F}$ & & $1.4672(3.1788)$ \\
\hline $\mathrm{t}$ & & $-4.2247(2.1009)$ \\
\hline
\end{tabular}

(Values in parentheses correspond to critical values tabulated for $\mathrm{p}=0.05$ ). 

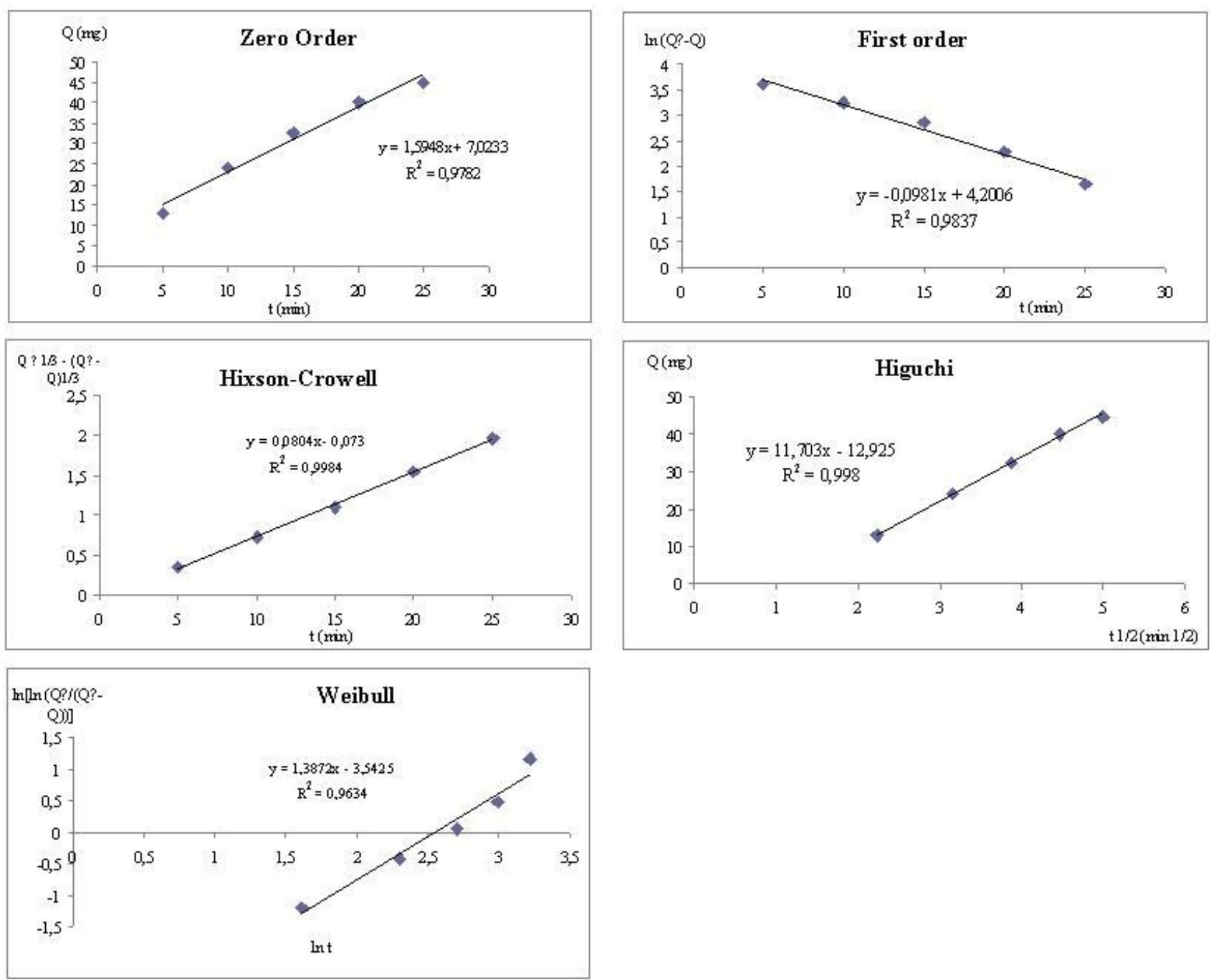

Fig. (6). Model-Dependent Methods.

Table 4. Comparisson of $\mathbf{r}^{2}$ and AIC for the studied kinetic models.

\begin{tabular}{|c|c|c|}
\hline Mathematical models & $\mathbf{r}^{2}$ & AIC \\
\hline \hline Zero order & 0,9782 & $-15,2552$ \\
\hline First order & $0,9837,1213$ \\
\hline Hixson-Crowell & 0,9984 & $-27,8613$ \\
\hline Higuchi & 0,9979 & 3,4225 \\
\hline Weibull & 0,9634 & $-6,6849$ \\
\hline
\end{tabular}

HPLC allowing dissolution testing without volume replacement. Diclofenac dissolution profile adjusts best to the Hixson-Crowell cube root model. Diclofenac tablet dissolution rate is very high, having $80 \%$ drug dissolution within 20 minutes.

\section{CONFLICT OF INTEREST}

The authors confirm that this article content has no conflict of interest.

\section{ACKNOWLEDGEMENTS}

This work was supported by a grant from the General Secretary of Science and Technology of the Northeastern National University (UNNE) and the National Council of Scientific and Technical Research (CONICET) of Argentina. All experiments were carried out in the Analytical Development and Quimiometry Laboratory (LADAQ) in Santa Fe. 


\section{REFERENCES}

[1] Lorenzo, P.; Moreno, A.; Leza, J.C.; Lizasoain, I.; Moro, M.A. Farmacología Básica y Clínica, 17 ed; Médica Panamericana: Spain, 2005.

[2] United States Pharmacopeia XXIV, National Formulary XX US Pharmacopeial Convention, Rockville, Maryland, 2002.

[3] Arcelloni, C.; Lanzi, R.; Pedercini, S.; Molteni, G.; Fermo, I.; Pontirolic, A. High-performance liquid chromatographic determination of diclofenac in human plasma after solid-phase extraction. $J$. Chromatogr. B., 2001, 763(1), 195-200.

[4] Kuhlmann, O.; Stoldt, G.; Struck, H.G.; Krauss, G.J. Simultaneous determination of diclofenac and oxybuprocaine in human aqueous humor with HPLC and electrochemical detection. J. Pharmaceut. Biomed., 1998, 17(8), 1351-1356.

[5] Blanco-Lopez, M.C.; Fernandez-Llano, L.; Lobo-Castanon, M.J. Potentiometric immunosensor using artificial antibody based on molecularly imprinted polymers. Anal. Lett., 2004, 37(5), 915-927.

[6] Mojtaba, S.; Fíame, J.; Sohrab, E. Preparation of a diclofenac potentiometric sensor and its application to pharmaceutical analysis and to drug recovery from biological fluids. J. Pharmaceut. Biomed., 2005, 37(5), 943-947.

[7] Solangi, A.R.; Memon, S.Q.; Mallah, A.; Khuhawar, M.Y.; Bhanger, M.I. Development and implication of a capillary electrophoresis methodology for ciprofloxacin, paracetamol and diclofenac sodium in pharmaceutical formulations and simultaneously in human urine samples. Biomed Chromatogr., 2009, 23(9), 1007-1013.

[8] Macia, A; Borrull, F; Calull, M; Aguilar, C. Capillary electrophoresis for the analysis of non-steroidal anti-inflammatory drugs. Trends in Anal. Chem., 2007, 26(2), 133-153.

[9] Aurora-Prado, M.S; Steppe, M; Tavares, M; Kedor-Hackmann, E; Santoro, M. Comparison Between Capillary Electrophoresis and Liquid Chromatography for the Determination of Diclofenac Sodium in a Pharmaceutical Tablet. J. AOAC. Int., 2002, 85(2), 333340

[10] Agatonović-Kuŝstrin, S.; Živanović, L.; Zečević, M.; Radulović, D. Spectrophotometric study of diclofenac-Fe(III) complex. J. Pharmaceut. Biomed., 1997, 16(1), 147-153.

[11] De Souza, R.; Tubino, M. Spectrophotometric determination of diclofenac in pharmaceutical preparations. J. Braz. Chem. Soc., 2005, 16(5), 1068-1073.

[12] Monzón, C.; Sarno, M.C.; Delfino, M. Diclofenac quantification: analytical attributes of a spectrophotometric method. Lat. Am. J. Pharm., 2011, 30(5), 1001-1004.
[13] Mayer, B.X.; Namiranian, K.; Dehghanyar, P.; Stroh, R.; Mascher, H.; Müller, M. Comparison of UV and tandem mass spectrometric detection for the high-performance liquid chromatographic determination of diclofenac in microdialysis samples. J. Pharmaceut. Biomed., 2003, 33(4), 745-754.

[14] Ma, S.; Zhu, M.M. Recent advances in applications of liquid chromatography-tandem mass spectrometry to the analysis of reactive drug metabolites. Chem. Biol. Interact., 2009, 179(1), 25-37.

[15] Sánchez, V.; Carreño, P.; Castelletto, M. Liberación y permeación de diclofenaco sódico desde matrices hidrofílicas. Acta. Farm. Bonaerense., 2001, 20(2), 101- 104.

[16] Rezende Schaffazick, S.; Raffin Pohlmann, A.; De Lucca Freitas, L.; Stanisçuaski Guterres, S. Caracterização e estudo de estabilidade de suspensões de nanocápsulas e de nanoesferas poliméricas contendo diclofenaco. Acta. Farm. Bonaerense., 2002, 21(2), 99106.

[17] Baccarin, M.; Evangelista, R.; Lucinda-Silva, R. Ethylcelullose microspheres containing sodium diclofenac: development and characterization. Acta. Farm. Bonaerense., 2006, 25(2), 401- 404

[18] Dos Santos, L.; Guterres, S.; Bergold, A. Caracterização e qualificação de diclofenaco de sódio como padrão secundário, Lat. Am. J. Pharm., 2007, 26(3), 355-361.

[19] Olivera, M.; Allemandi, D.; Manzo, R. Equivalencia farmacéutica en comprimidos recubiertos de diclofenac sódico, Acta Farm. Bonaerense. 2003, 22(2), 143-146.

[20] Farmacopea Nacional Argentina. 8va edición. ANMAT. 2011.

[21] Harris, D. C, Análisis químico cuantitativo, 3rd ed; Reverté: Barcelona, 2007.

[22] Lachmann, B., M. Kratzel, Noe, C.R. Rapid determination of diclofenac in pharmaceutical formulations by capillary zone electrophoresis. Sci. Pharm., 2012, 80(2), 311-316.

[23] Aguilar Ros, A; Caamaño Somoza, M; Martin-Martin, F.R; Montejo Rubio, M.C. Biofarmacia y Farmacocinética., 1ra. ed; Elsevier: Barcelona, 2008.

[24] Ostrowski, M.; Baczek, T. The Progress on the In Vivo-In Vitro Correlation (IVIVC) for Immediate Release Dosage Form as an Alternative to Bioavailability Studies. Curr. Pharm. Anal., 2010, 6(4), 289-298.

[25] Kumar, N.; Sangeetha, D.; Reddy, P.S.; Reddy A.M. Development and Validation of a Dissolution Test for Delayed Release Capsule Formulation of Duloxetine Hydrochloride. Curr. Pharm. Anal., 2012, 8(3), 236-246.

[26] Miller, J.C.; Miller, J.N. Estadística y Quimiometría para Química Analítica, 1ra. ed; Pearson-Prentice Hall: Madrid, 2000. 